\title{
Silicone versus acrylic resilient long term soft liners; a cross-over clinical study
}

\author{
Mohamed Hussein Abdelnabi ${ }^{1}$ and Amal Ali Swelem ${ }^{2}$
}

\author{
${ }^{I}$ Professor, Oral and Maxillofacial Prosthodontic Department, Faculty of Dentistry, King Abdulaziz \\ University, Jeddah, Saudi Arabia; and Removable Prosthodontic Department, Faculty of Dentistry, \\ Minia University, Egypt. \\ ${ }^{2}$ Professor, Oral and Maxillofacial Prosthodontic Department, Faculty of Dentistry, King Abdulaziz \\ University, Jeddah, Saudi Arabia; and Removable Prosthodontic Department, Faculty of Oral and \\ Dental Medicine, Cairo University, Egypt.
}

Received: 20 Oct. 2019/ Accepted 25 Dec. 2019/Publication date: 10 Jan. 2020

\begin{abstract}
Objective: The aim of this randomized controlled cross over study was to compare the effect of complete denture renewal using two different long term soft liners namely acrylic-based (ARL) and silicone-based (SRL). Conventional heat cured acrylic resin dentures (CAR) were used as control. Assessed parameters were categorized into objective clinical and subjective patient-centered variables. Clinical parameters were: maximum bite force (MBF) and masticatory efficiency (ME). Patient satisfaction (PS) was evaluated as a patient based outcome. Materials and methods: A total of 30 completely edentulous male patients were initially included in this randomized controlled cross over trial. All subjects already had dentures that lacked retention and stability. Each subject received 3 sets of complete dentures with similar occlusal and polished surfaces. Maxillary complete dentures were fabricated from conventional heat cured acrylic resin. The difference was in the material used in the fitting surface of the mandibular complete dentures: Group (Gp) I (CAR); Gp II (ARL); and Gp III (SRL). The order of the type of prosthesis received by each participant was randomized to achieve a cross over design. Each denture was followed up for 3 months (m) after final adjustment. A capacitive sensor was used to evaluate unilateral MBF. Sieve method was implemented for ME assessment. PS questionnaire evaluated 7 main items (comfort, esthetics, ability to speak, stability, ease of chewing, hygiene maintenance and overall satisfaction) using visual analogue scale. MBF and ME were assessed after 1, 2 and $3 \mathrm{~m}$ of denture wear after final adjustment. PS was evaluated $3 \mathrm{~m}$ postadjustment. Level of statistical significance was set at $p<0.05$. Results: 26 participants concluded the study. Renewed dentures in all groups showed significant improvement in all assessed parameters in comparison to the old prostheses. Improvements were statistically greater in (ARL) and (SRL) in comparison to (CAR) in MBF and ME in addition to 5 items of PS. Differences in esthetics were insignificant. PS was higher with hygiene maintenance in (CAR). Time had no significant effect on the results except after $3 \mathrm{~m}$. (SRL) in comparison to (ARL) showed significantly higher MBF and ME values. The differences in PS values, however, were insignificant. MBF and ME showed significant correlation. Conclusions: Renewal of defective complete dentures improved MBF, ME and PS. (ARL) and (SRL) were superior to (CAR) in MBF, ME and in most of PS outcomes. (CAR) scored better in hygiene maintenance. (SRL) performed better than (ARL) after 3 months in MBF and ME which might indicate better long term results.
\end{abstract}

Keywords: Complete denture renewal, soft liners, bites force, masticatory efficiency, patient satisfaction.

\section{Introduction}

Demographic and epidemiologic studies revealed an increase in the aging population. A projected increase in complete edentulism is expected in the upcoming years (Douglass et al., 2002; Peterson et al., 2005; Felton et al. 2011). As suggested in the McGill consensus statement, implant dentistry has revolutionized the management of tooth loss (Feine et al., 2002). However, implants are still not a practical line of treatment for millions of completely edentulous patients because of medical, financial or psychological limitations (Kimoto 2006). It is evident that complete dentures are still the most commonly used approach in the management of complete edentulism because of their acceptable effects on masticatory function, esthetics and phonetics (Palla et al., 2015). 
A significant number of complete denture wearers encounter difficulties with their prostheses. Complaints include inability to chew due to pain or lack of retention and stability. Such findings are more frequent with advanced ridge resorption and in cases with thin non resilient atrophic mucosa. Xerostomia further complicates the function of complete dentures (MacEntee et al., 2004; Forgie et al., 2005).

Soft liners have been suggested as an affordable solution to manage such problematic cases. These polymeric materials have the capacity to partially absorb energy of masticatory forces. The resultant even load distribution helps in recovery of inflamed tissues and significantly improve patient comfort (Wright, 1988; Kawano et al., 1993; Shim et al., 2000; Taguchi et al., 2001). These positive outcomes contributed to improvement in patient satisfaction (Kimoto et al. 2008) and in Oral Health Related Quality of Life (Pisani et al., 2012).

Soft liners could be broadly classified into short and long term varieties. The long term category could be used for 4 weeks, extended to months or even years. The most commonly used long term soft liners are basically acrylic- or silicone- based. Polymethacrylate materials are available as powder-liquid systems. Silicone based variety could be a one-component heat cured material (High Temperature Vulcanized- HTV), or a two paste system that cross links at room temperature (Room Temperature Vulcanized- RTV) (Braden et al., 1995).

The differences in composition and viscoelastic behavior of acrylic- and silicone- based soft liners resulted in different treatment outcomes. Reviewing the dental literature revealed that most of the studies carried out on these materials investigated their mechanical, physical and chemical properties (Chladek et al., 2014). Some studies assessed the impact of soft liners on masticatory function either subjectively or objectively. Subjective examinations resort to validated questionnaires and provide information about patients' self-assessed of chewing efficiency (Kimoto et al., 2010a; Udo-Yamakawa and Kawai, 2010). On the other hand, studies that objectively assessed masticatory function with resilient liners used methodologies including: sieving method, electromyography of masticatory muscles, mandibular kinesography and maximum biting force (Hayakawa et al., 2000; Murata et al., 2002, Kimoto et al., 2006; Kimoto et al., 2010b; Tata and Nandeeshwar, 2012; Pisani et al., 2013)

A limited number of studies compared the impact of the different types of resilient liners on masticatory function and on patient centered outcomes implementing randomized controlled study models (Palla et al., 2015). It was thus the aim of this randomized controlled cross over study to compare acrylic, silicone-based long term soft liners and conventional heat cured acrylic resin denture bases in cases indicated for complete denture renewal. Assessed objective variables included: maximum bite force (MBF) and masticatory efficiency (ME) as clinical outcomes. Patient satisfaction (PS) was evaluated as a patient-centered outcome. The null hypothesis was that the type of denture base will not affect any of the assessed parameters namely: MBF, ME, PS throughout the follow up period.

\section{Material and Methods}

Thirty male completely edentulous patients were consecutively enrolled in this randomized controlled cross-over study. Cases were selected from a number of private practices in addition to the outpatient clinic of Minia University. All cases presented to the clinic because of difficulties in the retention and stability of the mandibular complete dentures. Patients were offered renewal of their defective complete dentures free of charge.

The study was explained to the participants both verbally and in a written form. Alternative treatment options were clarified. Participants signed informed approval consents. The study design followed the University ethical committee guidelines.

Age of the enrolled subjects ranged between 56 and 71 with a mean of 64. Participants have been edentulous for at least 5 years with a minimum denture experience of 4 years. Panoramic radiographs were taken to assess mandibular bone height. Exclusion criteria included: 1. Patients with systemic disease that will compromise their capacity to adapt to new complete dentures; 2. Extensive xerostomia; 3. Advanced ridge resorption with mandibular bone height of $10 \mathrm{~mm}$ or less classified as Class IV based on the Prosthodontic Diagnostic Index (PDI) of the American College of Prosthodontists (McGarry et al., 1999). Included participants were non-bruxers and did not report any 
signs or symptoms of temporomandibular disorder (TMD). Residual ridges were free from excessive undercuts and without redundant mucoperiosteum. All included subjects had adequate inter-arch distance to accommodate the different types of complete denture bases with an Angle class I jaw relationship. None of the subjects suffered from allergy to acrylic resin or materials used in the soft liners.

This randomized controlled trial was designed with a cross over design. All participants received three sets of new complete dentures. In all groups, the maxillary complete dentures were constructed from conventional heat cured acrylic resin (Travelon, Dentsply). The difference between the groups was in the mandibular complete dentures : Gp I (CAR): conventional heat cured complete dentures; Group II (ARL): heat cured acrylic resin dentures relined with long term heat cured acrylic soft liner (Eversoft, Dentsply); Group III (SRL): mandibular heat cured acrylic resin dentures relined with long term heat cured silicone soft liner (Molloplast - B, Detax). The order of the type of denture received by each participant was selected using computer based randomization among the patients to comply with the requirements of a cross over study.

Dentures were constructed following a standard protocol. Alginate preliminary impressions were taken in stock trays. Final impressions were made in border molded special trays using green stick compound and the impression was taken with mono-phase polyvinyl siloxane. A face bow transfer was used to mount the maxillary cast. Centric and protrusive records were taken using the check bite technique. A Hanau semi-adjustable articulator was used to mount the casts for teeth arrangement. A bilateral balanced occlusion scheme was followed using semi-anatomic teeth. After the try in was found acceptable, dentures were processed using the compression molding technique. For dentures with resilient liners the manufacturers' instructions were followed. A $2 \mathrm{~mm}$ spacer was implemented at the resin packing stage to secure adequate thickness for the resilient liners. Both laboratory and clinical remounts were carried out to refine occlusion. The 3 sets of complete dentures fabricated were identical except for the material used to construct the fitting surface of the mandibular dentures. Silicone matrices were used to duplicate the position of teeth and the shape of the polished surfaces.

Denture adjustments were carried out until the patient did not report any complaints and the prosthodontist was satisfied with the inserted dentures. Patients were instructed to remove their dentures before going to sleep. Hygiene maintenance was emphasized. All participants were instructed not to use commercial denture cleaners. Mechanical cleaning with running water and a piece of thick gauze was the technique that was illustrated to them and they were asked to adhere to. This study assessed a number of clinical and patient-centered outcomes. Unilateral Maximum Bite Force (MBF), Masticatory efficiency (ME) and Patient Satisfaction (PS) were first recorded at the baseline with the old prosthesis. After each new denture was inserted and adjusted, participants were recalled on monthly basis for a period of 3 months to assess (MBF) and (ME). PS was reassessed only at the conclusion of follow up.

\section{Maximum Bite force (MBF)}

The iLoad Mini miniature load cell kit (Loadstar Sensors, Fremont, CA, USA) was used to measure the maximum bite force. It included a load cell with a rounded dome on top and with a flat bottom adapter, a DQ1000U frequency to USB interface that converts the frequency output from mini load cell into USB output and LV100 load VUE load cell display software which displays the data on a PC. The assembly is fully calibrated in compression mode. This type of load cells has the advantages of using capacitive sensing techniques. It offers high sensitivity in small sized tough packages that can withstand higher loads compared to electric resistor sensor with resistance strain gauge technology. The noise levels are reduced with a better output quality. This reduction facilitates packing more features into the sensors as digital communication modules and algorithms to convert raw signals into readily usable calibrated data and easy to use ASCII command set to access the finished data (Stefanescuand and Anghel, 2013).

Vertical MBF was measured at the recall visits on the complete dentures at the same location. The bite force transducer was covered with polyvinyl siloxane (PVS) dental impression material (Exafast, GC, IL, USA). This layer fitted each subject's denture. A reproducible position of the load cell at the different measurement sessions was thus secured. Occlusal stability was achieved with a PVS block with imprints of teeth of the other side placed during MBF measurements. The load cell was left to warm by connecting it to the power supply for at least 30 minutes before the measurement 
procedure. The sensor was then connected to PC through USB cable. The patient was seated in an upright position. Each measurement was repeated 3 times. The highest values for each side were recorded. A relaxation period of 10 minutes was given to obtain reliable MBF values (Geckili et al., 2012a; Geckili et al., 2012b).

\section{Masticatory efficiency (ME)}

ME was evaluated using filtered food remnant weight sieving method (Cheng et al., 2012a; Cheng et al., 2012b). $2.0 \mathrm{~g}$ of dried peanuts were weighted and packed in sealed plastic bags. Patients were directed to chew the $2.0 \mathrm{~g}$ of peanuts in $30 \mathrm{~s}$ and then expectorate the bolus in a dry container. The material was sieved through a $2.4 \mathrm{~mm}$ diameter holes filter. The remnants of the peanuts that did not pass through the sieve holes were dried in a desiccator at $60^{\circ} \mathrm{C}$ for $6 \mathrm{~h}$ and consequently weighed. Masticatory efficiency in terms of a percentage was determined using the formula: Masticatory efficiency $=[$ (Total weight - Remnant weight $) /$ Total weight $] \times 100 \%$. The procedure was repeated 3 times and then averaged to represent the masticatory efficiency.

\section{Patient satisfaction (PS)}

PS was evaluated at the baseline with the prosthesis that the patients had presented with. A second rating was carried out after 3 months of denture adjustment and use. This parameter was rated on a $100 \mathrm{~mm}$ Visual Analogue Scale (VAS). Zero corresponded to "completely dissatisfied". $100 \mathrm{~mm}$ at the opposite end of the scale represented "completely satisfied". Descriptors were anchored at each end of VAS. Patients rated each denture type as regards: comfort, esthetics, ability to speak, stability, ease of chewing, hygiene maintenance and overall satisfaction. The participants were blinded to their previous scores.

At the stage of patient recruitment, participants answered a socio-demographic questionnaire including: age, gender, marital status, educational level and occupation. Statistical analyses were conducted to assess whether these potential confounding variables affected patients' PS scores.

Statistical analyses were conducted using SPSS (Statistical Package for Social Sciences) (Version 15.0 for Windows, SPSS). Relevance of data to normal distribution was analyzed with Kolmogorov - Simrnov test. Data were expressed as means and standard deviations. ANOVA succeeded by post hoc Duncan multiple range statistical inferential tests were implemented for the normally distributed MBF and ME results. Kruskal Wallis followed by Dunn post hoc non-parametric tests were implemented to analyze patient satisfaction VAS scores as their distribution did not conform to a normal pattern. The possible relationship between MBF and ME was analyzed by Pearson's coefficient of correlation. The level of significance for statistical analyses was set at $p<0.05$.

\section{Results}

Twenty six of the initially 30 enrolled participants concluded the study. Contact was lost with 3 participants. These subjects did not show up after receiving their prostheses despite repeated attempts to communicate with them. 2 received as their first prosthesis heat cured acrylic resin dentures (CAR) and the third received acrylic resin long term resilient liner (ARL). The $4^{\text {th }}$ case did not remove the prosthesis during sleep on regular basis and showed unacceptable poor adherence to oral hygiene regulations. This case was thus excluded. This last patient received silicone long term resilient liner (SRL) as his first prosthesis.

The effect of type of denture base sequence on the different treatment outcomes was insignificant. Results were thus displayed cumulatively for each denture base material.

Unilateral MBF results in all groups showed significant improvement in comparison to the old prosthesis. Throughout the follow up period, significantly higher values were recorded in (ARL) and (SRL) in comparison to those obtained in (CAR). As for the effect of time, the differences between MBF after 1, 2 and 3 months of denture wear were insignificant for (CAR) and (SRL). The decline in MBF in (ARL) between 2 and 3 months was significant. Comparisons between (ARL) and (SRL) were also insignificant at all follow up periods except between 2 and 3 months (Table 1). 
Table 1: Unilateral maximum bite force in Newtons (Mean \pm SD) at baseline; 1, 2 and 3 months after denture adjustment.

\begin{tabular}{lcccc}
\hline Group & Old prosthesis & $\mathbf{1 m}$ & $\mathbf{2 m}$ & $\mathbf{3 m}$ \\
\hline (CAR) & $74 \pm 31^{\mathrm{Aa}}$ & $89 \pm 38^{\mathrm{Ab}}$ & $85 \pm 40^{\mathrm{Ab}}$ & $87 \pm 34^{\mathrm{Ab}}$ \\
(ARL) & $69 \pm 29^{\mathrm{Aa}}$ & $140 \pm 51^{\mathrm{Bb}}$ & $138 \pm 62^{\mathrm{Bb}}$ & $118 \pm 47^{\mathrm{Bc}}$ \\
(SRL) & $79 \pm 30^{\mathrm{Aa}}$ & $151 \pm 68^{\mathrm{Bb}}$ & $158 \pm 74^{\mathrm{Bb}}$ & $160 \pm 65^{\mathrm{Cb}}$ \\
\hline
\end{tabular}

$(\mathrm{CAR})=$ Conventional heat cured acrylic resin; $(\mathrm{ARL})=$ acrylic-based long term soft liners; $(\mathrm{SRL})=$ silicone-based long term soft liners; $m=$ month. Values with dissimilar capital letters in columns (between groups) show significant statistical differences. Values with dissimilar small letters in rows (between time intervals) show significant statistical differences. (ANOVA followed by post hoc Duncan multiple range statistical test $\mathrm{p}<0.05$ )

ME was calculated as the percentage of comminuted food particles that was able to pass through the sieve holes. As with MBF, ME improved in all groups after denture renewal irrespective of type of denture base. Comparing the different groups of renewed dentures, (ARL) and (SRL) showed significant improvement in contrast to conventional (CAR). In (CAR) and (SRL), the achieved improvement was stable with no significant differences after 1,2 and 3. On the other hand, in (ARL) a significant decline in ME was observed after 2 months of denture insertion. Differences between (ARL) and (SRL) were insignificant after 1, 2 months but significant after 3 months (Table 2).

Table 2: Masticatory efficiency \% (Mean \pm SD) at baseline; 1,2 and 3 months after denture adjustment.

\begin{tabular}{|l|c|c|c|c|}
\hline Group & Old prosthesis & $\mathbf{1 m}$ & $\mathbf{2 m}$ & $\mathbf{3 m}$ \\
\hline (CAR) & $47 \pm 21^{\mathrm{Aa}}$ & $51 \pm 22^{\mathrm{Ab}}$ & $52 \pm 18^{\mathrm{Ab}}$ & $50 \pm 21^{\mathrm{Ab}}$ \\
\hline (ARL) & $42 \pm 19^{\mathrm{Aa}}$ & $61 \pm 51^{\mathrm{Bb}}$ & $60 \pm 62^{\mathrm{Bb}}$ & $54 \pm 47^{\mathrm{Bc}}$ \\
\hline (SRL) & $45 \pm 27^{\mathrm{Aa}}$ & $64 \pm 31^{\mathrm{Bb}}$ & $64 \pm 24^{\mathrm{Bb}}$ & $68 \pm 65^{\mathrm{Cb}}$ \\
\hline
\end{tabular}

$(\mathrm{CAR})=$ Conventional heat cured acrylic resin; (ARL) = acrylic-based long term soft liners; (SRL) = silicone-based long term soft liners; $\mathrm{m}=$ month. Values with dissimilar capital letters in columns (between groups) show significant statistical differences. Values with dissimilar small letters in rows (between time intervals) show significant statistical differences. (ANOVA followed by post hoc Duncan multiple range statistical test $\mathrm{p}<0.05$ )

Analysis of the correlation between MBF and ME revealed statistical significance. Renewal of dentures resulted in significant improvement in patient satisfaction in all groups compared to the baseline levels with the old prosthesis. This improvement was observed in all assessed satisfaction parameters. However, when comparing groups at the end of the follow up period, the VAS scores in (ARL) and (SRL) in comparison to (CAR) showed statistically significant higher values in 5 items namely: comfort, ability to speak, stability, ease of chewing and overall satisfaction. Statistically significant better scores were observed in (CAR) in hygiene maintenance. Changes in between (ARL) and (SRL) were insignificant at the end of the follow up period (Table 3).

Table 3. Patient satisfaction VAS scores (Mean $\pm \mathrm{SD}$ ) at baseline and 3 months after denture adjustment.

\begin{tabular}{lcccc}
\hline Variable & Old prosthesis & (CAR) & (ARL) & (SRL) \\
\hline Comfort & $52 \pm 27^{\mathrm{A}}$ & $62 \pm 21^{\mathrm{B}}$ & $82 \pm 26^{\mathrm{C}}$ & $85 \pm 27^{\mathrm{C}}$ \\
Esthetics & $62 \pm 32^{\mathrm{A}}$ & $78 \pm 34^{\mathrm{B}}$ & $94 \pm 32^{\mathrm{B}}$ & $92 \pm 26^{\mathrm{B}}$ \\
Ability to speak & $59 \pm 25^{\mathrm{A}}$ & $71 \pm 25^{\mathrm{B}}$ & $89 \pm 28^{\mathrm{C}}$ & $91 \pm 29^{\mathrm{C}}$ \\
Stability & $48 \pm 25^{\mathrm{A}}$ & $60 \pm 19^{\mathrm{B}}$ & $79 \pm 21^{\mathrm{C}}$ & $88 \pm 31^{\mathrm{C}}$ \\
Ease of chewing & $42 \pm 19^{\mathrm{A}}$ & $54 \pm 22^{\mathrm{B}}$ & $85 \pm 34^{\mathrm{C}}$ & $91 \pm 17^{\mathrm{C}}$ \\
Hygiene maintenance & $65 \pm 22^{\mathrm{A}}$ & $79 \pm 29^{\mathrm{B}}$ & $68 \pm 30^{\mathrm{C}}$ & $72 \pm 22^{\mathrm{C}}$ \\
Overall satisfaction & $47 \pm 28^{\mathrm{A}}$ & $61 \pm 22^{\mathrm{B}}$ & $87 \pm 35^{\mathrm{C}}$ & $90 \pm 34^{\mathrm{C}}$ \\
\hline
\end{tabular}

$(\mathrm{CAR})=$ Conventional heat cured acrylic resin; (ARL) $=$ acrylic-based long term soft liners; $(\mathrm{SRL})=$ silicone-based long term soft liners. Values with dissimilar capital letters in rows (between groups) show significant statistical differences. (Kruskal Wallis followed by Dunn post hoc non-parametric statistical tests $\mathrm{p}<0.05$ )

Statistical analysis of the potential confounding variables including: age, marital status, educational level and occupation between the three study groups were insignificant. The results of the study could thus rather be contributed to the type of denture base. 


\section{Discussion}

This study followed a randomized controlled cross over and not a parallel design to increase the statistical power. In addition to the well-known advantages of the randomization and including a control group, the cross over design has the merit of minimizing the effects of wide variability among the baseline findings of the included subjects. This is especially valid in factors involved in determining prognosis of complete dentures because of the wide diversity of the pattern of residual ridge form, height, configuration, adaptive neuromuscular capacity and other factors. On the other hand, a downside of the cross over design is the limited period available for the each of the 3 denture base types that extended to 3 months for each type. (Macura-Karbownik et al., 2016; Fueki et al., 2017). Another reason for the relatively short follow up period was to minimize the possible effects of time on residual ridge resorption and consequently the retention and stability of the prostheses (Tallgren et al., 2003; Tumrasvin et al., 2006).

In this randomized controlled trial, MBF and ME were used to objectively assess the masticatory functional state. Variables reported to that affect MBF and ME included: occlusal factors (such number of opposing occlusal units and occlusal force (Slagter et al., 1993a; Bakke, 2006; Paphangkorakit et al., 2008); factors related to dental prostheses type and quality (Slagter et al., 1993b); incorporating implants in the treatment protocol (van Kampen et al., 2002); presence and severity of temporomandibular disorders (TMDs) (Ahlberg et al., 2003) and neuromuscular disease (Granger et al., 1999). All subjects included in this study were free of TMDs and neuromuscular disease to exclude the adverse effects of such factors on the study outcomes. The cross over design of this investigation made the type of denture base the most probable sole factor affecting the outcomes. In this investigation, all subjects were males to exclude gender as a confounding variable.

This study showed that MBF, ME and PS were higher after denture renewal irrespective of the type of denture base material. This finding is in agreement with other studies that similarly reported the positive impact of denture renewal especially when the old dentures were defective. The improvement in satisfaction ratings was observed in all assessed parameters. This could be attributed to the defective quality of the old prostheses as patients sought denture renewal because of inadequate retention and stability that rendered their dentures dysfunctional (Peltola et al., 1997; Gunji et al., 2009; Bonnet et al., 2016).

Subjective and objective methodologies have been implemented to assess masticatory function. Subjective assessment is carried out by asking patients questions related to chewing food (Hatch et al., 2000). Objective evaluation of masticatory performance include a number of methodologies as: sieve method (Cheng et al., 2012a; Cheng et al., 2012b), color changes in test food as chewing gum (Hayakawa et al., 1998), sugar loss from chewing gum (Heath., 1982), dye release when chewing carrots using a colorimetric method (Kayser and Hoeven, 1977), color changes quantification by photometric methods (Nakasima et al., 1998), and optical scanning of chewed particles (van der Bild et al., 1993). In the study at hand, and in the majority of chewing performance studies, ME was assessed by the sieve method. A similar methodology has been used by Cheng et al., (2012a; 2012b). Synthetic materials have been suggested to avoid possible variations in consistency because of seasonal and geographical variations (Fontijn-Tekamp et al., 2000). It was however preferred to use a natural product provided by a single supplier and stored in closed packages at constant temperature and humidity. The advantage was that patients were accustomed to that normally consumed product. (Hatch et al., 2000).

It is important to critically analyze the methodology of the recording technique when comparing studies assessing MBF (Bakke, 2006). Factors include: location of MBF measurement within the dental arch and the number of teeth included (Ferrario et al., 2004), in addition to bite force transducer dimensions (thin pressure-sensitive sheet versus bite transducer) (Shinogaya et al., 2000; Ikebe et al., 2005). In the current study, the same calibrated transducer was utilized throughout the trial. The transducer was positioned in the same location for each patient by a customized layer of impression on surfaces of the transducer contacting the occlusal surfaces of teeth (van Kampen et al., 2002); van der Bilt et al., 2008). Another variable is whether the measurement was unilateral or bilateral. Bilaterally measured MBF was found to be $30 \%-40 \%$ greater than the unilateral readings (van der Bild et al., 2008).

In this short term study, both acrylic- and silicone- based liners were comparable in the first 2 months in their impact on both objective and subjective parameters. The resilient liner groups were superior to that of the conventional hard acrylic denture type in the objectively parameters namely MBF and ME. This 
finding could be interpreted by the more evenly distributed load to the underlying mucosa reported with soft liners, which relieves the supporting structures from excessive mechanical stress and thus increases MBF and ME (Murata et al., 2002; Kimoto et al., 2006; Shinomiya et al., 2006).

At the 3 month follow-up period, the silicone-based liners significantly surpassed the performance of acrylic-based variety in both MBF and ME. Nonetheless, this difference in patient satisfaction was insignificant. The differences that were observed first after 3 months could be attributed to the chemical properties of the acrylic-based liners. The plasticizers used in this type of soft liners are not bound to the resin and would thus leach out with time with a consequent decline in the initial favorable viscoelastic properties (Phoenix, 2003; Mante et al., 2008; Mese and Guzel, 2008). Kimoto et al. (2010b) reported a similar interpretation to the findings of their randomized controlled trial that investigated how acrylicbased resilient liners (ARL) affected masticatory ability of complete denture wearers as compared to the conventional heat cured acrylic resin variety (CAR). Masticatory performance was assessed using the sieve method. They concluded that the masticatory ability several months after denture insertion were poorer compared to that at the time of denture insertion as the material had already lost the initial softness. After about a period of 5month post insertion, the differences between (ARL) and (CAR) were insignificant.

Murata et al. (2002) in a short tem study compared a number of short and long term soft liners to hard resins one week after denture insertion. The clinical assessed parameters included maximum bite force using the Dental Prescale System, chewing time and patient satisfaction. Resilient liners were superior to hard dentures in all assessed variables which in accordance with the findings of the study at hand. They reported, however, better findings with permanent acrylic liners than those with the silicone variety. This result could be interpreted by the short term of their study. A longer observation period might have changed the outcome.

The temporary nature of (ARL) has been emphasized in a study dedicated to investigating the survival rate of mandibular complete dentures with this material. Kimoto et al. (2013) in a long-term randomized controlled study compared the longevity of (ARL) to that of (CAR). They concluded that this type of liners doubled the risk of shortening the denture survival time. They also reported that around 27 months after denture insertion, participants complained from stains and roughness of the liner that necessitated a remake. The type of denture cleaner and the frequency of its use, in addition to the brushing method resulted in variation in stain and roughness frequency. In the current study, the authors standardized the nature and frequency of maintaining hygiene to minimize variations related to that factor (Oliveira et al., 2007; Brozek et al., 2011).

Kimoto et al. (2006) in a randomized controlled trial verified the effect of silicone- based resilient liners on masticatory function. This type of liners significantly improved masticatory performance based on the results of sieve test, a finding that is in accordance with the study at hand. Kimoto et al., (2006) interpreted the improved masticatory efficiency by the prolonged early stage occluding period, which is a critical phase of the chewing cycle. These early stages are particularly difficult for denture wearers as the food bolus still has its initial size and texture which impose high pressure on the supporting structures (Takayama et al., 2001; Nishigawa et al., 2003).

In the study at hand, a significant correlation was found between MBF and ME. Fontijn-Tekamp et al., (2000) and Hatch et al., (2000) reported the large influence of bite force on masticatory performance in subjects with conventional complete dentures, overdentures as well as natural dentition. It was thus concluded that bite force explains over $60 \%$ of variance in masticatory performance.

Participants in the current study assessed their complete dentures 3 months after insertion. This period was adequate for patients' adaptation to take place and thus give stable responses to satisfaction questionnaires (Kimoto et al. 2010a). The construct and content validity of the questionnaire used in this trial has been established in previous studies (de Grandmont et al., 1994). High test re-test reliability has been confirmed (Awad and Feine, 1998).

Patient satisfaction with both types of soft liners was higher than that with the hard conventional acrylic resin denture base with the exception of hygiene maintenance. Differences in esthetic assessment between conventional and resilient liner groups were insignificant. A logical explanation would be that the used materials were related to the denture fitting surface which had no impact on esthetics. The higher satisfaction in most of the parameters could be attributed to the better load distribution and the cushioning effect of the soft liners in comparison to the hard unforgiving nature of the hard conventional variety. Moreover, the enhanced retention and stability reported for dentures with resilient liners further improved 
chewing and speaking ability. These observations are in agreement with other studies that evaluated patient-centered outcomes including patient satisfaction (Schmidt and Smith, 1983; Kimoto et al., 2004; Kimoto et al., 2014), patient preference (Kimoto et al., 2014), perceived chewing ability (Kimoto et al., 2010a; Kimoto et al., 2014) and Oral Health Related Quality of Life (OHRQoL) (Murata et al. 2002; Pisani et al., 2013; Krunic et al., 2015).

Hygiene maintenance of the soft relined dentures is one of the difficulties that complete denture wearers encounter. The low surface hardness and consequently reduced resistance to scratches, porosity, and high water sorption in addition to the detrimental effects of common denture cleaners are the reasons behind such drawbacks. These shortcomings were not reported in the conventional acrylic resin group (Oliveira et al., 2007; Brozek et al., 2011). This explains why patient were more satisfied with their (CAR) as regards this aspect.

A number of factors were reported as potential confounding variables that might affect patient satisfaction. These factors include: age, marital status, educational level and occupation (Walton et al., 2009). The socio-demographic questionnaire identified such variables. Statistical analyses were conducted to ensure that these variables did not significantly impact participants' scores.

\section{Conclusion}

Within the limitations of this study, it was concluded that renewal of defective complete dentures improved MBF, ME and PS in comparison to the old complete dentures. (ARL) and (SRL) were superior to (CAR) in MBF, ME and in most of the patient-centered PS outcomes. (CAR) scored better in hygiene maintenance. (SRL) performed better than (ARL) after 3 months in MBF and ME which might indicate better long term results.

\section{References}

Ahlberg, J.P., O.A. Kovero, K.A. Hurmerinta, I. Zepa, M.J. Nissinen and M.H. Kononen, 2003. Maximal bite force and its association with signs and symptoms of TMD, occlusion, and body mass index in a cohort of young adults. Cranio.,21:248-252.

Awad, M.A. and JS. Feine, 1998. Measuring patient satisfaction with mandibular prostheses. Community Dent Oral Epidemiol., 26:400-405.

Bakke, M., 2006. Bite force and occlusion. Semin Orthod.,12:120-126

Bonnet, G., C. Batisse, J.W. Segyo, J.L. Veyrune, E. Nicolas and M. Bessadet, 2016. Influence of the renewal of removable dentures on oral health related quality of life. Springerplus, 28, 5(1):2019.

Braden, M., P.S. Wright and S. Parker, 1995. Soft lining materials -A review. Eur. J Prosthodont. Restor. Dent., 3, 163-174.

Brozek, R., R. Koczorowski, R. Rogalewicz, A. Voelkel, B. Czarnecka and J.W. Nicholson, 2011. Effect of denture cleansers on chemical and mechanical behavior of selected soft lining materials. Dent Mater, 27: 281-290.

Chladek, G., J. Zmudzki and J. Kasperski, 2014. Long-Term Soft Denture Lining Materials. Materials (Basel), 12;7(8):5816-5842.

Cheng, T., L. Ma, X. L. Liu, G.F. Sun, X.J. He, J .Y. Huo and Y.N.Wang, 2012a. Use of a single implant to retain mandibular overdenture: A preliminary clinical trial of 13 cases. J Dent., 7: 261266.

Cheng, T., G. Sun, J. Huo, X. He, Y. Wang and Y.F. Ren, 2012b. Patient satisfaction and masticatory efficiency of single implant-retained mandibular overdentures using the stud and magnetic attachments. J Dent., 40:1018-23.

de Grandmont, P., J.S. Feine, R. Taché, et al., 1994. Within-subject comparisons of implantsupported mandibular prostheses: psychometric evaluation. J Dent Res., 73:1096-104.

Douglass, C.W., A. Shih and L. Ostry, 2002. Will there be a need for complete dentures in the United States in 2020? J Prosthet Dent., 87:5-8

Feine, J.S., G.E. Carlsson, M.A. Awad, A. Chehade, W.J. Duncan, S. Gizani, T. Head, G. Heydecke, J.P. Lund, M. MacEntee, R. Mericske-Stern, P. Mojon, J.A. Morais, I. Naert, A.G. Payne, J. Penrod, G.T. Stoker, A. Tawse-Smith, T.D. Taylor, J.M. Thomason, W.M. Thomson and D Wismeijer, 2002. The McGill consensus statement on overdentures. Mandibular two-implant 
overdentures as first choice standard of care for edentulous patients. Int J Oral Maxillofac Implants, 17:601-2.

Felton, D., L. Cooper, I. Duqum, G. Minsley, A. Guckes, S. Haug, P. Meredith, C. Solie and D. Avery and N. Deal Chandler, 2011. Evidence based guidelines for the care and maintenance of complete dentures. J Prosthodont., 20:1-12.

Ferrario, V.F., C. Sforza, G. Serrao, C. Dellavia and G.M. Tartaglia, 2004. Single tooth bite forces in healthy young adults. J Oral Rehabil., 31:18-22.

Fontijn-Tekamp, F.A., A.P. Slagter, A. van der Bilt, M.A. van`t Hof, D.J. Witter, W. Kalk, J.A. Jansen, 2000. Biting and chewing in overdentures, full dentures, and natural dentitions. J Dent Res., 79:1519-1524.

Forgie A.H., B.J. Scott and D.M. Davis, 2005. A study to compare the oral health impact profile and satisfaction before and after having replacement complete dentures in England and Scotland, Gerodontology, 22, 137-142.

Fueki, K., E. Yoshida-Kohno and N. Wakabayashi, 2017. Oral health-related quality of life in patients with non-metal clasp dentures: a randomised cross-over trial. J Oral Rehabil., 44(5):405-413.

Granger, M.W., P.H. Buschang, G.S. Throckmorton and S.T. Iannaccone, 1999. Masticatory muscle function in patients with spinal muscular atrophy. Am J Orthod Dentofac Orthop., 115:697-702.

Geckili, O., H. Bilhan, E. Mumcu, C. Dayan, A. Yabul and N. Tuncer, 2012a. Comparison of patient satisfaction, quality of life, and bite force between elderly edentulous patients wearing mandibular two implant-supported overdentures and conventional complete dentures after 4 years. Special Care in Dentistry, 32: 136-141.

Geckili, O., H. Bilhan, E. Mumcu and N. Tuncer, 2012b. The Influence of Maximum Bite Force on Patient Satisfaction and Quality of Life of Patients Wearing Mandibular Implant Overdentures. Journal of Oral Implantology, 38: 271-277.

Gunji, A., S. Kimoto, H. Koide, H. Murakami, Y. Matsumaru, K. Kimoto, M. Toyoda, K. Kobayashi, 2009. Investigation on how renewal of complete dentures impact on dietary and nutrient adequacy in edentulous patients. J Prosthodont Res., 53(4):180-4.

Hatch, J.P., R.S.A. Shinkai, S. Sakai, J.D. Rugh and E.D. Paunovich, 2000. Determinants of masticatory performance in dentate adults. Arch Oral Biol., 46:641-648.

Hayakawa, I., I. Watanabe, S. Hirano, M. Nagao and T. Seki, 1998. A simple method for evaluating masticatory performance using a color-changeable chewing gum. Int J Prosthodont., 11:173-176.

Hayakawa, I., S. Hirano, Y. Takahashi and E.S. Keh, 2000. Changes in the masticatory function of complete denture wearers after relining the mandibular denture with a soft denture liner. Int $\mathbf{J}$ Prosthodont, 13: 227-231.

Heath, M.R., 1982. The effect of maximum biting force and bone loss upon masticatory function and dietary selection of the elderly. Int Dent J., 32:345-356.

Ikebe, K., T. Nokubi, K. Morii and J. Kashiwagi, 2005. Association of bite force with ageing and occlusal support in older adults. J Dent., 33:131-137.

Kawano F., A. Koran, K. Asaoka and N. Matsumoto, 1993. Effect of soft denture liner on stress distribution in supporting structures under a denture, Int. J. Prosthodont., 6, 43-49.

Kayser, A.F. and V. Hoeven, 1977. Colorimetric determination of the masticatory performance. J Oral Rehabil., 4:145-148. 54.

Kimoto, S., M. Kitamura, M. Kodaira, S. Yamamoto, Y. Ohno, Y. Kawai, M. Kawara, K. Kobayashi, 2004. Randomized controlled clinical trial on satisfaction with resilient denture liners among edentulous patients, Int. J. Prosthodont. 17, 236-240.

Kimoto S., S.O. Kimoto, K. Kimoto, S. Yamaoto, Y. Onho, M. Shimomiya, K. Ogura, K. Kobayashi, 2006. Randomized controlled clinical trial for verifying the effect of silicone based resilient denture liner on the masticatory function of complete denture wearers, Int. J. Prosthodont., 19(6): 593-600

Kimoto, S., K. Kimoto, A. Gunji, Y. Kawai, H. Murakami, K. Tanaka, K. Syu, H. Aoki, M. Tani, M. Toyoda and K. Kobayashi, 2008. Effects of resilient denture liner in mandibular complete denture on the satisfaction ratings of patients at the first appointment following denture delivery, J. Jpn. Prosthodont. Soc., 52, 160-166.

Kimoto, S., K. Kimoto, A. Gunji, M. Shinomiya, T. Sawada, M. Saita and K. Kobayashi, 2010a. Randomized controlled trial investigating the effect of an acrylic-based resilient liner on 
perceived chewing ability in edentulous patients wearing mandibular complete dentures. Int $\mathrm{J}$ Prosthodont, 23:110-116.

Kimoto, S., S. Yamamoto, M. Shinomiya and Y. Kawai, 2010b. Randomized controlled trial to investigate how acrylic-based resilient liner affects on masticatory ability of complete denture wearers. J Oral Rehabil., 37:553-559.

Kimoto, S., K. Kimoto, A. Gunji, Y. Kawai, H. Murakami, K. Tanaka, K. Syu, H. Aoki, M. Toyoda and K. Kobayashi, 2007. Clinical effects of acrylic resilient denture liners applied to mandibular complete dentures on the alveolar ridge. J Oral Rehabil., 34:862-869.

Kimoto, S., K. Kimoto, H. Murakami, A. Gunji, N., Ito and Y. Kawai, 2013. Survival analysis of mandibular complete dentures with acrylic-based resilient liners. Gerodontology., 30(3):187-93

Kimoto, S., K. Kimoto, H. Murakami, G. Atsuko, A. Ogawa and Y. Kawai, 2014. Effect of an acrylic resin-based resilient liner applied to mandibular complete dentures on satisfaction ratings among edentulous patients. Int J Prosthodont., 27(6):561-6.

Krunic, N., M. Kostic, M. Petrovic and M. Igic, 2015. Oral health-related quality of life of edentulous patients after complete dentures relining. Vojnosanit Pregl., 72(4):307-11.

MacEntee M.I., Nolan A., Thomason J.M, 2004., Oral mucosal and osseous disorders in frail elders, Gerodontology, 21, 78-84.

Macura-Karbownik, A., G. Chladek, J. Zmudzki and J. Kasperski, 2016. Chewing efficiency and occlusal forces in PMMA, acetal and polyamide removable partial denture wearers. Acta Bioeng Biomech., 18(1):137-44.

Mante, F.K., M.O. Mante and V.C. Petropolous, 2008. In vitro changes in hardness of sealed resilient lining materials on immersion in various fluids. J. Prosthodont., 17, 384-391.

McGarry, T.J., A. Nimmo, J.F. Skiba, R.H. Ahlstrom, C.R. Smith and J.H. Koumjian, 1999. Classification system for complete edentulism. The American College of Prosthodontics. J Prosthodont, 8:27-39.

Mese, A. and K.G Guzel, 2008. Effect of storage duration on the hardness and tensile bond strength of silicone- and acrylic resin-based resilient denture liners to a processed denture base acrylic resin. J. Prosthet. Dent., 99, 153-159.

Murata H., N. Taguchni, T. Hamada, M. Kawamura and J.F. McCabe, 2002. Dynamic viscoelasticity of soft liners and masticatory function, J. Dent. Res., 81(2), 123-128.

Nakasima, A., K. Higashi, M. Ichinose, 1989. A new, simple and accurate method for evaluating masticatory ability. J Oral Rehabil., 16:373-380.

Nishigawa, G., T. Matsunaga, Y. Maruo, M. Okamoto, N. Natsuaki and S. Minagi, 2003. Finite element analysis of the effect of the bucco-lingual position of artificial posterior teeth under occlusal force on the denture supporting bone of the edentulous patient. J Oral Rehabil., 30:646652.

Oliveira, L.V., M.F. Mesquita, G.E. Henriques and R.L. Consani, 2007. The effect of brushing on surface roughness of denture lining materials. J Prosthodont, 16: 179-184.

Palla, E.S., E. Karaoglani, O. Naka and V. Anastassiadou, 2015. Soft denture liners' effect on the masticatory function in patients wearing complete dentures: A systematic review. J Dent., 43(12):1403-10.

Paphangkorakit J., N. Chaiyapanya, P. Sriladlao and S. Pimsupa, 2008. Determination of chewing efficiency using muscle work, Arch. Oral Biol., 53(3): 533-537.

Peltola, M.K., A.M. Raustia and M.A. Salonen, 1997. Effect of complete denture renewal on oral health--a survey of 42 patients. J Oral Rehabil., 24(6):419-25.

Petersen, P.E., D. Bourgeois, D. Bratthall and H. Ogawa, 2005. Oral health information systemstowards measuring progress in oral health promotion and disease prevention. Bull World Health Organ, 83:686-693

Pisani, M.X., L. Malheiros-Segundo Ade, K.L. Balbino, R.F. de Souza, F. Paranhos Hde and C.H. da Silva, 2012. Oral health related quality of life of edentulous patients after denture relining with a silicone-based soft liner, Gerodontology, 29, 474-480.

Pisani, M.X., A.L. Segundo, V.M. Leite, R.F. de Souza, M.A. da Silva and C.H. da Silva, 2013a. Electromyography of masticatory muscles after denture relining with soft and hard denture liners, J. Oral Sci., 55, 217-224. 
Phoenix, R.D, 2003. Denture base resins. In Phillips' Science of Dental Materials, $11^{\text {th }}$ ed.; Anusavice, K., Ed.; Saunders: St. Louis, MO, USA, pp. 750-752.

Schmidt WF Jr and D.E. Smith, 1983. A six-year retrospective study of Molloplast-B-lined dentures. Part I: Patient response. J Prosthet Dent. 1983 Sep,50(3):308-13.

Shim, J.S. and D.C. Watts, 2000. An examination of the stress distribution in a soft-lined acrylic resin mandibular complete denture by finite element analysis. Int J Prosthodont., 13:19-24.

Slagter, A.P., F. Bosman, H.W. van der Glas and A. van der Bilt, 1993a. Human jaw elevator muscle activity and food comminution in the dentate and edentulous state. Arch Oral Biol., 38:195-205.

Slagter A., F. Bosman and A. Bilt, 1993b. Comminution of two artificial test foods by dentate and edentulous subjects, J. Oral Rehabil., 20(2): 59-76.

Shinogaya, T., M. Bakke, C.E. Thomsen, A. Vilmann and M. Matsumoto, 2000. Bite force and occlusal load in healthy young subjects - a methodological study. Eur J Prosthodont Restor Dent., 8:11-15.

Shinomiya, M., 2006. In-vivo and in vitro studies for analysis of mastication in complete denture wearers with resilient denture liners, Int. J. Oral-Med. Sci., 2(5): 107-116.

Stefanescu, D.M. and M.A. Anghel, 2013. Electrical methods for force measurement - A brief survey; Measurement., $46: 949-959$.

Taguchi, N., H. Murata, T. Hamada and G. Hong, 2001. Effect of viscoelastic properties of resilient denture liners on pressures under dentures. J Oral Rehabil., 28: 1003-1008.

Takayama, Y., T. Yamada, O. Araki, T. Seki and T. Kawasaki, 2001. The dynamic behaviour of a lower complete denture during unilateral loads: Analysis using the finite element method. J Oral Rehabil., 28: 1064-1074.

Tallgren, A., 2003. The continuing reduction of the residual alveolar ridges in complete denture wearers: a mixed-longitudinal study covering 25 years, J. Prosthet. Dent., 89(5), 427-435.

Tata, S. and D.B. Nandeeshwar, 2012, A clinical study to evaluate and compare the masticatory performance in complete denture wearers with and without soft liners, J. Contemp. Dent. Pract. 13, 787-792.

Tumrasvin, W., K.,Fueki and T. Ohyama, 2006. Factors associated with masticatory performance in unilateral distal extension removable partial denture patients, J. Prosthodont., 15(1), 25-31.

Udo-Yamakawa A. and Y. Kawai 2010, Effects of home and office care denture reliners on maxillary complete dentures, Gerodontology, 27, 141-146.

van der Bilt, A., H,W, van der Glas, F, Mowlana and M.R. Heath,1993. A comparison between sieving and optical scanning for the determination of particle size distributions obtained by mastication in man. Arch Oral Biol., 38:159-162.

van der Bilt, A., F.A. Tekamp, H.W. van der Glas and J.H. Abbink, 2008. Bite force and EMG during maximum unilateral and bilateral clenching. Eur J Oral Sci., 116:217-222.

van Kampen, F.M.C., A. van der Bilt, M.S. Cune and F. Bosman, 2002. The influence of various attachment types in mandibular implant-retained overdentures on maximum bite force and EMG. J Dent Res., 81:170-173.

Walton, J.N., N. Glick and M.I. MacEntee, 2009. A randomized clinical trial comparing satisfaction and prosthetic outcomes with mandibular overdentures retained by one or two implants. Int $\mathbf{J}$ Prosthodont, 22:331-339.

Wright, P.S., 1994. Observations on long-term use of a soft lining material for mandibular complete dentures. J Prosthet Dent., 72: 385-392. 